\title{
Perceived value of support for older adults coping with multi-morbidity: patient, informal care-giver and family physician perspectives
}

\author{
GAYATHRI NAGANATHAN*, KERRY KULUSKI*†, \\ ASHLINDER GILL*, LIISA JAAKKIMAINEN $\$ \$ \|$, \\ ROSS UPSHUR $\dagger+\|^{* *}$ and WALTER P. WODCHIS*\|I
}

\begin{abstract}
This study investigated the perceived value of informal and formal supports for older adults with multi-morbidity from the perspectives of patients, care-givers and family physicians. Semi-structured interviews were conducted with 27 patients, their informal care-givers and their family physicians in an urban academic family health team in Ontario. Analysis was conducted using a General Inductive Approach to facilitate identification of main themes and build a framework of perceived value of supports. Participant views converged on supports that facilitate patient independence and ease care-giver burden. However, important differences in participant perceptions arose regarding these priorities. Physicians and care-givers valued supports that facilitate health and safety while patients prioritised supports that enable self-efficacy and independence. While formal supports which eased care-giver burden were viewed positively by all members of the triad, many patients also rejected formal supports, citing that informal support from their care-giver was available. Such conflicts between patient, care-giver and physician-perceived value of supports may have important implications for consumer and care-giver willingness to accept formal supports when supports are available. These findings contribute to the broader literature on community-based care by incorporating the perspectives of patients, informal
\end{abstract}

* Institute of Health Policy, Management \& Evaluation, University of Toronto, Canada.

$\dagger$ Lunenfeld-Tanenbaum Research Institute, Sinai Health System, Toronto, Canada.

\$ Department of Family and Community Medicine, University of Toronto, Canada.

$\S$ Sunnybrook Academic Family Health Team, Sunnybrook Health Sciences Centre, Toronto, Canada.

|| Institute for Clinical Evaluative Sciences, Toronto, Canada.

**Dalla Lana School of Public Health, University of Toronto, Canada.

I Toronto Rehabilitation Institute, Canada. 
care-givers and family physicians to understand better the barriers and facilitators of uptake of supportive services that contribute to successful ageing at home.

KEY WORDS - primary care, multi-morbidity, ageing at home, home care, qualitative research.

\section{Introduction}

Global patterns of mortality and disease prevalence have shifted significantly from infectious diseases to chronic conditions with chronic diseases accounting for 63 per cent of global mortality in recent years (World Health Organization 2011; Yach et al. 2004). Multiple chronic conditions increase significantly with age and older adults with multiple chronic conditions are frequent users of health care and incur great health-care costs (Fortin et al. 2005; Glynn et al. 2011; König et al. 2013; Lehnert et al. 2011 ; Ward and Schiller 2013).

This trend is particularly apparent in the primary care setting where the prevalence of adult patients with multi-morbidity is higher than patients with isolated diseases (Fortin et al. 2005; Rizza et al. 2012). With the global share of older people estimated to nearly double by $205^{\circ}$, the challenge of treating older adults with multi-morbidity will increasingly tax health-care systems worldwide (United Nations Department of Economic and Social Affairs, Population Division 2013).

Social support has been shown to improve health outcomes for older adults in several areas including mental health (Kwag et al. 2011 ), cognitive function (Zhu, Hu and Efird 2012 ), quality of life (Chan et al. 2005), morbidity (Tomaka, Thompson and Palacios 2006) and mortality (Maier and Klumb 2005). Models of health-service delivery which emphasise and incorporate social support have been shown to decrease health-care expenditures (Shier et al. 2013). More effectively incorporating social support into existing chronic disease service models may decrease health-care costs and improve outcomes for ageing populations. Home and community-based care systems are one such model which provides formal health and social support services (Martin-Matthews, Sims-Gould and Tong 2013; Williams et $a$ l. $2009 b$ ). While there are a multitude of definitions of social support, this study approaches social support broadly as 'support', and operationalises it as emotional or instrumental support, including assistance with activities of daily living (ADLs) such as eating and bathing, and with instrumental activities of daily living (IADLs) such as transportation. Furthermore, this study distinguishes between formal (paid) support and informal (unpaid) support, and includes both in this analysis. 


\section{Canadian context for home and community care}

While all medically necessary care, including physician and hospital care, is assured by the Canada Health Act, receipt of home and community care is not a universal entitlement and is significantly less organised. Individuals rely on various government-financed, private-pay and informal care services to support their medical and non-medical needs when not in hospital or being cared for by a physician. In the absence of a national home-care policy in Canada, home-care reforms are taking place, more or less, within each of the provinces (Martin-Matthews, Sims-Gould and Tong 2013).

Currently, home care in Ontario, Canada is provided by a number of sources including the government, private sector, informal care-givers and volunteers. Community Care Access Centres (CCACs) organise government-funded home-care services including professional care (nursing, occupational therapy, physiotherapy, etc.), home-making and personal support services to support ADLs (eating, bathing, toileting and personal hygiene) for persons who cannot complete these tasks due to physical and/or cognitive impairments (Mercer 20o8; Ministry of Health and Long-term Care 20o6). Over time, CCACs have increasingly provided more medicalised, post-acute care rather than chronic disease management due to budget constraints (Williams et al. 2oogb). CCACs generally do not provide support for IADLs including meals, home maintenance, transportation, etc., which instead are provided by a number of grassroots community support agencies who may charge a user fee (Williams et al. 2009b).

Informal care-givers, in particular, are key to maintaining and supporting seniors in the community, and provide a number of different supports including emotional support and assistance with ADLs and IADLs (Canadian Institute for Health Information 2011). However, the most recent Home Care Reporting System data suggest that almost a third of care-givers providing home care to Ontarians reported symptoms of care-giver distress and an additional 12 per cent expressed that they were unable to continue taking on the care-giver role (Canadian Institute for Health Information 2013).

While home-care utilisation among seniors is high compared to nonsenior adults, among these seniors, utilisation of home-care services varies considerably based on social and geographical factors such as income and geographic setting. An Ontario case study summarised patient-reported reasons for unmet home-care needs such as wait times and cost but also included reasons such as 'didn't get around to it', 'decided not to seek' and 'would be inadequate' (Yu 2011). This suggests that while health-care utilisation may depend on a number of different factors including affordability and accessibility, patient perceptions of the value of particular services may also play a role. Recent research from China also reported that 
disparities in health-service utilisation are influenced, in part, by patient-perceived value of the medical service (Qian et al. 2011). While a large body of evidence suggests that social support is needed to age in place successfully (Kuluski et al. 2012), how recipients value such support remains unclear.

Given the increasing prevalence of multi-morbidity in the primary care setting and the key role played by informal care-givers in the care of seniors with multi-morbidity, a better understanding of how patients, informal caregivers and family physicians perceive support services could inform the design and implementation of care that may better address patient needs.

\section{Purpose of the study}

In the Ontario context, older adults with multi-morbidity have a clearly defined medical system of care but less is understood about how, when and why they make use of formal and informal home and community care supports. Our interest is in uncovering these questions and in understanding how the perceived value of various formal and informal supports influences the role of social support in people's lives.

Qualitative inquiry is particularly suited to examining individuals' perceptions of value and to identify non-financial barriers and facilitators of patient uptake of various health services (Money et al. 2013; Schultz et al. 2012). As such, this exploratory qualitative study aims to understand how patients, informal care-givers and family physicians perceive the value of various formal and informal supports for older adults with multi-morbidity.

\section{Methods}

\section{Setting and data collection methods}

This study was conducted at a family health team (FHT) clinic within a tertiary academic health centre in Toronto, Ontario. Convenience sampling was employed to recruit participants who were willing to share their lived experience. Two office co-ordinators screened patient rosters to select eligible patients ( $6_{5}$ years of age or older, and diagnosed with two or more chronic conditions). Each family physician in the FHT completed secondary screening of patients from their respective rosters to confirm patient capacity to provide informed consent, presence of informal care-giver and patient English proficiency.

\section{Participant recruitment}

Eligible patients were either contacted by an office co-ordinator over the phone or in person by a member of the FHT to gain verbal consent for a research 
associate to approach the patient. The research associate explained the study, scheduled the patient interview and obtained consent from the patient to contact their informal care-giver (family, friend, etc.). Prior to completing the patient interview, the research associate also contacted the informal caregiver over the phone or in person to discuss the study and schedule an interview. All participants were interviewed separately either in a private room in the FHT clinic or at the participant's home. Of the eligible patients, 35 individuals provided verbal agreement to participate and scheduled an interview. However, seven of these participants withdrew from the study for various reasons including a lack of care-giver availability or interest and patient health decline. In all, 28 patients, 28 care-givers and four physicians were included in the interviews. The four family physicians were interviewed once per participating patient in their roster. Of the 28 patients, one chose not to complete the interview but remained enrolled in the study. Therefore, only 27 of the 28 patient-caregiver-physician triads were included for qualitative analysis.

Semi-structured interviews were conducted with all members of the patient-care-giver-physician triad (Kuluski et al. 2013a). The interview guide was adapted from an instrument developed by the Bridgepoint Collaboratory for Research and Innovation and modified to include questions on care experiences, social support and the perceived value of different types of support (home care, family care-givers, friends/neighbours and community programmes), goals of care and frustrations experienced while managing multi-morbidity. This guide was previously piloted at another institution to ensure its validity to elicit patient responses (Kuluski et al. 2013 , 2014). The transcript produced based on the entire interview guide was analysed with a special focus on questions pertaining to social support. Quantitative measures of social support included rating the importance of various care providers on a five-point scale, with 1 being not important and 5 being critical. Qualitative measures of social support included open-ended questions such as 'Can you tell me a little more about the support you receive from your family and/or friends?'

\section{Data analysis}

Descriptive statistics were carried out on the quantitative data from the interview guides including participant demographic data. The question regarding rating importance was also meant to introduce the variety of supports of interest for the study and the general focus on the importance of each source of support. These were further elaborated using open-ended questions. Given the small sample size, descriptive summaries of the data are included to supplement the themes reported in the qualitative analysis. Further quantitative analyses were not conducted. 
Interviews were transcribed verbatim by an independent transcriptionist and verified by two research associates (AG, GN). Qualitative data (openended interview content) pertaining to support in care were analysed using NVivo 1o (QSR International) using a General Inductive Approach (Thomas 2006).

Initial open coding was done with a particular emphasis on generating in vivo codes from the data rather than applying a pre-determined coding matrix. In subsequent rounds of abstraction, well-established concepts in the literature, such as ADLs, were incorporated into the coding scheme where appropriate. Main themes were identified and categorised by one research associate (GN), and reviewed by two other authors (KK, AG) over multiple team meetings to improve reliability of the analysis and interpretation of the data (Green and Thorogood 20o9: 221). The main themes were iteratively abstracted and integrated, and deviant cases were explored further to strengthen the emerging framework and to add rigour to the analysis. Several analytical memos were also generated to aid theory development and to document researcher reflexivity. The framework (discussed below in detail) was developed through constant comparison across interviews and across participant groups. The framework also facilitated triangulation of the findings to determine where the views of different participant groups in the therapeutic alliance converged and/or diverged.

\section{Results}

\section{Participant characteristics}

Patients were on average 82.3 years of age (standard deviation $(\mathrm{SD})=7 \cdot 7$ ) The majority of patients were male $(57 \%)$ and were diagnosed with a median of five chronic conditions (interquartile range $=3^{-7}$ ). Informal care-givers were on average $70.5(\mathrm{SD}=11.3)$ years of age. The majority of informal care-givers were female $(82 \%)$ and were mostly spousal care-givers $(61 \%)$. The majority of both patients $(70 \%)$ and care-givers $(64 \%)$ had higher education (more than high school) and lived in a single family home (70 and $79 \%$, respectively). As well, 19 per cent of patients, 29 per cent of care-givers and $4^{6}$ per cent of physicians reported that the patient was currently receiving home care through the CCAC at the time of the interview (Table 1). Discrepancy between patient self-reports and medical records of patients are well documented in the literature, particularly for elderly patients (Haapanen et al. 1997; Iecovich and Biderman 2013; Kriegsman et al. 1996; Okura et al. 2004). Those participants in this study who reported not receiving home care commented on past experiences with home care or the expected importance of home-care services in the future. 
TABLE 1. Patient, care-giver and family physician reports of support received from various providers/sources

\begin{tabular}{|c|c|c|c|c|}
\hline & Home care & $\begin{array}{l}\text { Family } \\
\text { care-giver }\end{array}$ & $\begin{array}{l}\text { Friends and } \\
\text { neighbours }\end{array}$ & Community programmes \\
\hline & & & Frequencies (\%) & \\
\hline Patients $(\mathrm{N}=27)$ & $5(19)$ & $26(96)$ & $19(70)$ & $7(26)$ \\
\hline $\begin{array}{l}\text { Care-givers } \\
\quad(\mathrm{N}=28)\end{array}$ & $8(29)$ & $26(93)$ & $16(57)$ & $10\left(3^{6}\right)$ \\
\hline $\begin{array}{l}\text { Family physicians } \\
\qquad(\mathrm{N}=28)\end{array}$ & $13\left(4^{6)}\right.$ & $26(93)$ & $16(57)$ & $13(46)$ \\
\hline
\end{tabular}

\section{A framework for perceived value of support: perceptions of the 'unit of care'}

Patient, informal care-giver and family physician narratives regarding support broadly focused on the importance of patient independence, concern regarding care-giver burden and burnout, the importance of social participation, and health and safety. Participants had a variety of experiences and views on informal and formal supports as they relate to these main themes. The framework for perceived value of support (outlined in Figure 1) incorporates the views of informal care-givers, family physicians and patients, and examines areas of convergence and divergence of their views. As highlighted in Figure 1, patient, informal care-giver and physician views aligned on two main themes; positive views of support that facilitates patient independence, and positive views of support that reduces caregiver burden. Both care-givers and patients had positive views of support that facilitated participation in social networks while this was less of a priority for physicians. Additionally, physicians and care-givers both expressed positive views of support that facilitated health and safety of patients and negative views of support that hindered patient health and safety. Each of the central themes that emerged is included in Figure 1 and described in detail in this section.

\section{Supports facilitating independence}

All participants had positive views of supports that facilitated patient independence. For example, one informal care-giver discussed the importance of the retirement home that her mother lives in, emphasising that it allows her mother to maintain independence and participate in various activities:

You know, she continues to be happy here and continues to be active. This building allows her to be active as much as she wants to be. You know, she plays bridge three times a week, and cribbage ... You know, independent living is good. (oo4C) 


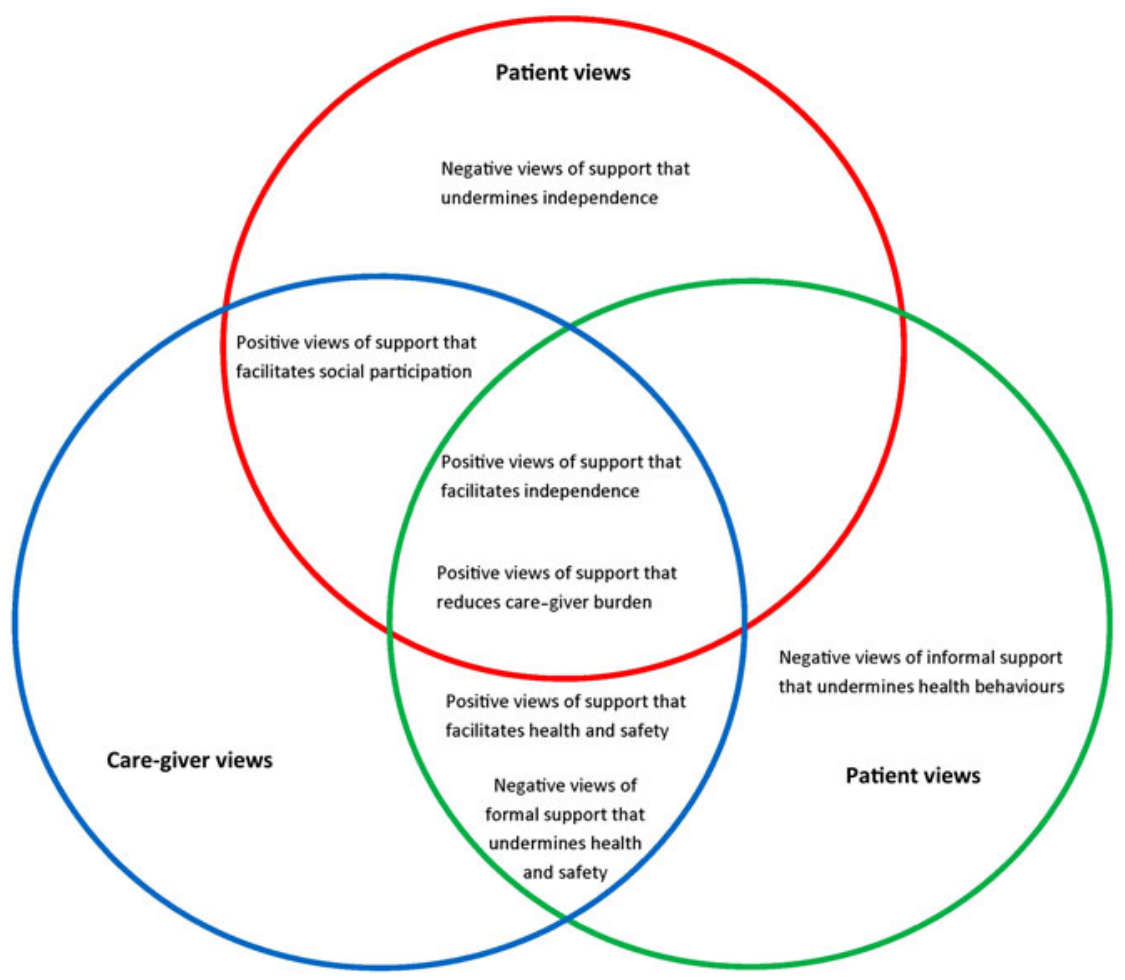

Figure 1. Framework of patient, care-giver and family physician views of informal and formal supports.

However, while care-givers and physicians viewed formal supports as facilitating patient independence, patients often resisted additional formal supports. The same care-giver emphasised that while her mother was resistant to being placed in the high-needs portion of the care facility, the informal care-givers involved in her care had positive views of these additional supports and thus transitioning her mother into the high-needs portion of the facility in the future would be a point of tension:

She tells me that she doesn't want to go over to the [name of institution], which is the more care portion of this facility ... They have a dining room over there, and there's no cooking in the apartments over there. So it's sort of an ... not an extended care but people who need a little more help are over there. And she doesn't ... She's never wanted to be there ... So you know, I don't know what we're going to do if and when the opportunity arises that we have to make a change for her. $\left({ }^{\circ} 4 \mathrm{C}\right)$

In addition, patients expressed negative views of informal supports which undermine their independence or control over their own circumstances. The loss of her driver's licence significantly decreased independence for 
a widowed 91-year-old female patient, and she was uncomfortable accepting support with transportation:

That really knocked the wind out of me, not being able to drive. It changed everything. It took away my independence. I mean [my son] is so good about taking me when I want to go shopping anywhere but I don't feel right dragging him through the women's department and trying on clothes and things like that. $\left({ }_{0}{ }_{3} \mathrm{P}\right)$

Similarly, some physicians expressed that while institutional care may be necessary to maintain independence, patients and care-givers were sometimes resistant to this transition. Discussing a 71-year-old homebound patient coping with hearing loss, visual impairment and depression, his family physician expressed that,

Giving him independence is a real goal of care. We've also struggled with him and his wife as to whether he should consider moving to a facility where he might get more support. (oO4 $\mathrm{FP}$ regarding $\mathrm{O}_{4} \mathrm{P}$ )

Patients who lived in their own homes also emphasised that they wanted to stay at home and avoid institutional care. This was echoed by both caregivers and physicians. However, physicians added that while patients had a desire to stay in their own homes, they were not always willing to accept the necessary supports to maintain their health at home. One family physician expressed that both the patient and his wife were resistant to formal supports such as Lifeline, which is an in-home medical alert service for older adults allowing them to easily access services in cases of emergencies:

So they want to stay at home but they won't consider something like Lifeline. They want to stay at home but they decline all the CCAC services to go in. (oo4 FP regarding $\mathrm{O} 3 \mathrm{OP}$ )

In addition, most participants discussed negative views related to support or assistance with routine tasks such as keeping track of appointments. Often patients connected accepting assistance with perceived cognitive decline. An 86-year-old patient was resistant to acknowledging the need for support or accepting support, even from his wife:

No, no, I [book appointments] myself ... I'm not incompetent ... I don't need to go to [my wife] when I need help. We discuss things. And there's no going to her when I need help. She's aware of my interests and likewise. (oo1 P)

An 85-year-old patient coping with arthritis and high blood pressure also emphasised that independence was particularly important to her and was aware that her rejection of assistance created some tension with health providers:

Other than my family doctor saying I had to have help, and me stubbornly saying, no, I think I can look after myself just because I like to be independent. I don't like 


\section{Gayathri Naganathan et al.}

people doing things for me. I like to do it myself. It's not that I don't appreciate it but I like to be able to and would make every effort to do things for myself rather than accepting help. Everything is appreciated but I think you know what I mean. (oo $7 \mathrm{P})$

\section{Supports easing care-giver burden}

Patient, care-giver and physician perspectives also aligned with respect to supports that ease care-giver burden. Typically, formal supports for IADLs such as home-making and transportation were reported to reduce caregiver burden and improve relationships between informal care-givers and the patient:

I mean Wheel-Trans is the other big thing that has freed me up and made me less resentful. When she got on the transit, it was huge. (oo3 $\mathrm{C}$ )

Wheel-Trans is a transit service provided through the Toronto Transit Commission in Toronto, Canada, that provides door-to-door accessible transportation service for individuals with physical disabilities leading to impaired functional mobility (Toronto Transit Commission 2015).

Similarly, her mother expressed that the availability of formal transportation services reduced the burden of care placed on her daughter:

I was thinking before I should mention how grateful I am for Wheel-Trans. I am not using it as much now as I used to because I don't go out. And my daughter tries to make herself available but she is working ... But I am very grateful for Wheel-Trans. (oo3P)

Other care-givers expressed positive views of supports which provided assistance with care-giving tasks that were beyond the care-giver's ability. A $77^{-}$ year-old care-giver, whose husband was bedbound, discussed the personal support worker services that her husband receives through their privatesector home-care service:

It's critical because I don't have the strength to look after him. He's also incontinent quite often. Not all the time but quite often. And I can't move him. It's very difficult for me. (oogC)

Physicians focused their discussion more generally on care-giver burnout and the capacity for formal supports to reduce the likelihood of burnout. Furthermore, they expressed that those patients who rely heavily or exclusively on support from their informal care-giver tend to increase care-giver burden and risk care-giver burnout. The family physician of an 85 -year-old patient discussed the significant pressure to provide care that the patient's daughter experienced:

And so one of my goals of care would be to have her healthy enough so that she's not killing her daughter because her daughter is very stressed helping her manage. And 
she's not that sick, [patient name]. She's really quite ... She's pretty high functioning. But I think she has unrealistic expectations of her daughter. Refuses to accept help from other people when people are offering. And then the burden falls to the daughter. (oo2 FP regarding $0_{00} \mathrm{P}$ )

This particular patient (as previously discussed) emphasised the importance of independence and the need to manage her needs without too much support or help from others. Thus, there appears to be some discrepancy in patient-perceived level of independence and actual degree of support required.

Furthermore, physicians discussed care-giver resistance to formal support, despite the risk of care-giver burnout. For example, a 91-year-old care-giver who was looking after her 85 -year-old husband and was relatively isolated from other potential family care-givers, was against bringing formal supports into the home:

There's no family in the city so she's sort of managing this all by herself. And she's very resistant to help ... Wouldn't hear of respite care, won't hear tell of moving. And they're in a two-storey [name of neighbourhood] home. They have a dog. (oo4 FP regarding $016 \mathrm{P}$ )

Although physician narratives predominantly discussed the importance of formal supports to decrease care-giver burden, one physician suggested that formal services such as home care were less important because the patient's informal care-giver was engaged:

Yes, he gets help from his family care-giver. That's a 5 . And I think that's why home care is a 1 , because she's doing an excellent job. (oo2 FP regarding ${ }_{033} \mathrm{P}$ )

This physician assigned home-care services a low rating not based on the quality of the services provided, but based on the perceived necessity of home-care services. In the quantitative portion of the interview a ' 1 ' on the five-point scale of the importance of supports indicates 'not important', while and rating of ' 5 ' indicates that the support is perceived to be 'critical' to the patient's health and wellbeing.

This dichotomy between informal and formal supports also emerged in patient narratives. Patients expressed that formal supports were unnecessary as long as informal support from their care-giver was available. An 83-yearold widowed patient expressed this regarding the support that her daughter provided with IADLs such as cooking and cleaning:

I:

$\mathrm{R}:$

I:

$\mathrm{R}:$
And have you used any day programmes like recreation programmes, meals, care from a group or anything like that?

No. Because I'm living with my daughter, I don't need it.

And any assistance with meals or cleaning?

Well, not when I'm with her. (O12P) 


\section{Supports facilitating social participation}

Participation in social networks was also emphasised, particularly by patients and care-givers. Engaging in activities with social networks such as hobby groups and participation in alumni associations was highlighted as being important. A patient who had undergone radiation therapy for breast cancer expressed the limitations that her illness had placed on social participation:

Just to get back like feeling like a human being because I've just been like a zombie for the last almost a year now ... I have had what amounts to no social life at all and none of the activities that define me as a person available because I can't get to them. $(011 \mathrm{P})$

In addition, patients and care-givers expressed the growing importance of social networks as patients continue to age and experience health decline. A care-giver in her late seventies discussed social participation as a means to connect to the past and to the world:

[friends and neighbours] become a critical element the older you get because they offer that connection to your past or to your activities, to your interface with the world if you like ... I would say you'd be very alone if you didn't have some connection with your friends. (002C)

As such, supports which allowed patients to participate in their social networks were viewed positively by patients and care-givers. This was expressed by care-givers of patients living in their own homes in the community, and by care-givers of patients living in retirement facilities. A care-giver providing support to her husband who has Alzheimer's expressed the positive impact of participation in social programmes on her husband:

There is a chap coming up from [organisation]. And he comes two days a week for three hours a day. And that's helped [husband]. [Husband] really enjoys his company ... And I can see a big difference in [husband] after he's been there. (o16C)

Similarly, a care-giver whose 93-year-old mother lives in a retirement home felt that the facility provided her with a sense of community where she could participate in all of the social activities that are meaningful to her:

Any of the activities, whether it's cooking or going over to the mall or having a sing song or going down to a movie or playing bridge, all of the social activities she may have done in her old home are here. Except that they're even better because somebody will come in with a travel log on Africa for example ... So she's reliant on [retirement residence] as her community. (o2oC)

Additionally, while family physicians supported social participation of patients, and typically rated friends and neighbours as well as community programmes as being important or critical (Figure 2), they did not discuss the importance of social participation in depth and it appeared to 


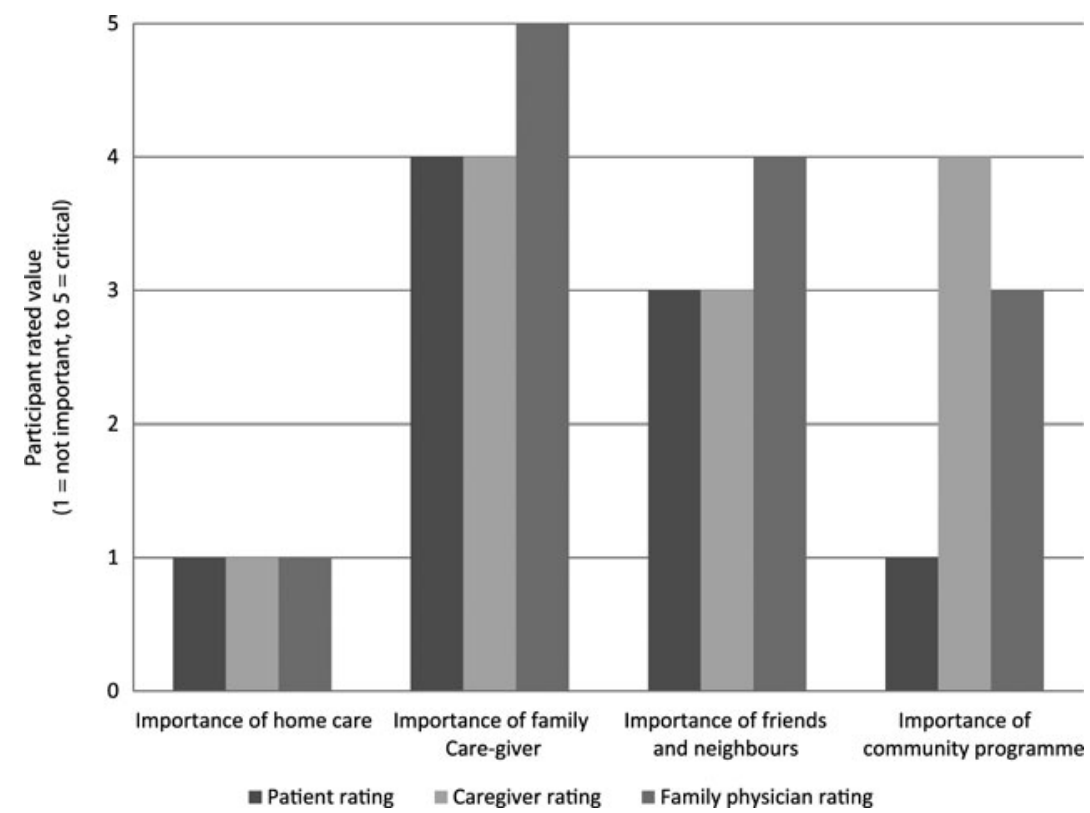

Figure 2. Importance attributed to various service providers as reported by patients, care-givers and family physicians.

be a secondary concern for physicians. One physician mentioned that friends and neighbours are critical because he was aware that his patient's neighbour is attentive and watchful for any problems the patient might face:

Friends and neighbours are critical. There's a neighbour who actually keeps an eye on her. (oo1 FP regarding $012 \mathrm{P}$ )

\section{Supports facilitating health and safety}

Physicians and care-givers discussed support that facilitated health and safety of patients. Overall, support from informal care-givers, such as assistance with health planning, was viewed as important for patient health. A physician noted that the care-giver of a 68-year-old patient coping with Crohn's disease often played an important role in navigating the health system:

His wife is very critical with helping him navigate. He comes mostly alone but when things are sketchy and not going well, she'll be there. And I know I can pick up the phone and talk to her. (oo1 FP regarding ${ }_{01}{ }_{3} \mathrm{P}$ )

Many care-givers also discussed the support they provide as being critical to the health of the patient. Specifically, care-givers viewed their patient advocate role as an important support which facilitated health and safety of the 


\section{Gayathri Naganathan et al.}

patient. A care-giver of a 78-year-old patient who used a wheelchair as his primary mode of locomotion discussed the system barriers and hurdles she faced while obtaining sufficient home-care services for her husband and the immense burden this placed on her and her husband:

I mean right now, he is receiving excellent care. It took a lot of fighting and battles and phone calls and letters to the WSIB [Workplace Safety and Insurance Board] ... Frustration was very high and very long through the years because of WSIB's not really getting involved or providing the help that he would have needed. Like he had to fight. And we went through a lot of stress in our personal lives because of that. That he needed the help and it wasn't provided or it was denied. So the frustration level is a lot less or a lot lower right now because of the help he is getting. But like I said, it's only the past six months. Where the past 15 years was very hard. $\left(\mathrm{o}_{4} \mathrm{C}\right)$

Beyond the patient advocate role, informal care-givers also discussed the various ADL and IADL functions they perform which support and facilitate patient health:

So my goal certainly is to support him to go to all of his appointments and to keep track of his health, and to feed him well ... So that's my role. And I certainly prepare the things that I think will be low in caloric intake and meet his needs that way. (o02C)

In addition, care-givers discussed the tension that can arise with the patient due to differences of opinion regarding healthy and safe behaviours. The daughter of a 96-year-old patient coping with arthritis, high blood pressure and glaucoma among other conditions, discussed that she was watchful of her father's activities, fearing he would over-exert himself:

Oh, I would think that the main frustration would be power struggles between the two of us where I'm concerned about his safety. And you know, he's pretty good. He's pretty sensible ... I mean he needs to be independent ... But that line between what's prudent and safe is a grey one at best. And sometimes we navigate that line a little differently. (o34C)

As well, overburdened care-givers in particular expressed that formal supports such as personal support workers were critical for the health of their loved one. A care-giver, whose husband was homebound due to his mobility issues and severe depression, discussed the importance of formal support for his mental and physical health:

And it's mainly personal care but it's also to keep him company, to have someone with him through the day. And like I said, when I'm saying that he's in a better spirit and he's more himself, it's due to the fact that someone is with him in the house. He doesn't feel so isolated and helpless ... I don't think he would be able to survive or probably would be back in a deep depression if he didn't have the care that he's receiving now. So it's critical for him, yes. $\left(\mathrm{or}_{4} \mathrm{C}\right)$

Additionally, physicians expressed negative views of supports that they perceived as undermining patient health and safety. Particularly, physicians 
expressed frustration with uncooperative patients and informal care-givers when trying to provide adequate care for the patient. The physician of an 83-year-old patient with Parkinson's disease was particularly concerned with the patient's risk of falling. However, the patient's family care-givers did not share this concern:

A little bit of frustration just because I'm so worried about him having a bad fall and all that that would mean for him. Yet I can't seem to get him and his family to realise just how much of a reality that fall is. $\left(\mathrm{oO}_{4} \mathrm{FP}\right.$ regarding $\left.\mathrm{o}_{3} \mathrm{OP}\right)$

Physicians also expressed that some necessary supports are difficult to access due to health system limitations. Some care-givers also echoed these concerns. The 61-year-old daughter of a male patient coping with arthritis and cataracts, among other conditions, suggested that some home-care services were organised in such a way that patients could not access necessary supports without first experiencing further health decline:

[Home-care organisation] doesn't do anything unless you're under their care all the way. He doesn't need to be under their care ... He doesn't need anybody to come in and bathe him and wash him and cook his meals. He does need somebody to come in and clean the place. It's a bachelor apartment. So help would be better if the place was clean. I can't get the place cleaned unless I make him really, really ill. So that doesn't work. (o33C)

\section{Ratings of support}

In addition to the convergence and divergence of participant views in the qualitative data, similar trends were observed in the quantitative rating of the importance of various supports. Patient, care-give, and physician assessments of value aligned with respect to home care, as all participant groups most often reported that home care was 'not important' (Figure 2). In contrast, patients and care-givers rated family care-givers as being 'very important' while physicians rated family care-givers as 'critical'. Interestingly, while patients generally viewed community programmes (formal supports) as 'not important', physicians and family care-givers generally viewed these programmes as 'important' or 'very important,' respectively.

\section{Discussion}

\section{Barriers and facilitators of support services uptake}

In this study, older patients with multi-morbidity, their care-givers and their primary care physicians discussed a variety of supports provided by formal and informal sources. Participant narratives largely converged on positive views of supports that facilitated patient independence and positive views 
of supports that eased care-giver burden. However, there were often differences of opinion as to whether supports facilitated independence or undermined it. This was exemplified by patient resistance to additional supports in the home such as LifeLine or medicine reminders. Care-givers and physicians viewed these additional supports as a means for patients to age at home successfully while maintaining independence and capacity. In contrast, patients, and some care-givers, perceived these supports as undermining patient independence or capacity to manage their own environment. These findings are also reflected in the quantitative data where all participant groups most often rated formal supports such as home care lower than informal supports such as family care-givers. These findings build on recent work by Byrne et al. which qualitatively explored patient-perceived value of home care in British Columbia and found that patients valued services which allowed them to preserve their autonomy and independence, allowing them to care for themselves on their 'good days' (2012: 388).

The differences in patient and care-giver/physician perspectives on the value of additional supports may also be related to patient self-efficacy. Warner et al. (2011) recently reported that for older adults with low perceived self-efficacy (perception of one's capacity to complete an action to obtain a desired outcome) social support reinforced patient autonomy. Conversely, those with high self-efficacy viewed support as undermining autonomy (Warner et al. 2011 ). While all participant groups in this study expressed positive views of supports that facilitated patient independence, there were important differences between patients, care-givers and physicians on how patient independence is best supported and this may be related to patient self-efficacy and autonomy. Thus, patients may be resistant to services that they perceive as undermining their independence or autonomy.

Supports which eased care-giver burden were viewed positively by all members of the triad. Most often, formal supports such as personal support workers eased care-giver burden by providing ADL support that informal care-givers did not have the capability to perform. Interestingly, these supports not only eased care-giver burden, but also were able to improve patient-care-giver relationships, reducing negative emotions such as resentment. Of note, in cases where patients perceived themselves to be a burden to their informal care-givers, formal supports were more readily accepted by patients. In contrast, patients who relied heavily on support from informal care-givers often rejected available formal supports. This is also reflected in the quantitative data where patients most often gave community programmes a low rating while physicians and care-givers rated these programmes higher. Informal care-givers may value community programmes because they facilitate social participation and also decrease caregiver burden by providing ADL and IADL supports that would normally fit 
within the care-giver role. In contrast, patients may perceive community programmes as having no or little value because informal care-givers are present and able to provide the same supports that the programmes offer.

While care-giver burden has been a major focus of research, policy and programme-development in Canada (Etters, Goodall and Harrison 20o8; Lilly et al. 2012; Ministry of Health and Long-term Care 2010; Sims-Gould and Martin-Matthews 2010; Sinha 2013), the uptake of services designed to offset care-giver burden may be hindered by patient over-estimation of care-giver capacity. Additionally, although patient preference is valued in the patient-centred care model (Epstein and Peters 20og; Ontario Medical Association 2010), these findings demonstrate the need to balance the competing priorities of patient preference for informal support and care-giver burnout potential in order to manage ageing at home successfully.

Patients and care-givers both expressed positive views of supports that facilitated social participation, emphasising that greater social participation contributed to better health and wellbeing. This finding echoes previous research which reported the decline of social participation with age among older adults and the negative effects of social isolation and loneliness on health outcomes (Kwag et al. 2011; Tomaka, Thompson and Palacios 2006). Similarly, care-givers and physicians expressed positive views of both formal and informal supports that facilitated patient health and safety. This echoes recent work done by Lopez et al. (2013), which examined the perspectives of family caregivers of nursing home residents with dementia and showed that family caregivers were first concerned with procuring basic care and ensuring patient safety before prioritising issues such as patient autonomy and self-efficacy, akin to Maslow's Hierarchy of Needs (Maslow 1943). Additionally, physicians and care-givers expressed negative views of formal supports which undermine patient health and safety due to misalignment of patient needs and available services. Thus, uptake of the services may also be hindered by ineffective structuring of support services delivered through home care.

\section{Examining the views of patients, care-givers and physicians}

This study is novel in that it examines the perspectives of patients, informal care-givers and family physicians serving this vulnerable population. Aligning patient preferences to treatment has been shown to improve uptake of appropriate treatments, patient satisfaction and health outcomes, particularly for mental health care (Kwan, Dimidjian and Rizvi 2010; Watsford and Rickwood 2014).

In the context of community-based care, the importance of informal caregivers for older adults has been emphasised, suggesting that the expansion of the 'unit of care' to include both the patient and informal care-giver is 
necessary (Williams et al. 2009a). The geriatric literature has particularly emphasised the importance of the patient-care-giver dyad and presents both the patient and care-giver as the unit of treatment across multiple care settings including psychiatry, oncology and palliative care (Chappell and Funk 2011 ; Surbone, Baider and Kagawa-Singer 2010). The importance of the informal care-giver suggests that care-giver preferences and perspectives should also be explored. The current study is unique in that it explores both patient and care-giver views with respect to the perceived value of supports available to the patient-care-giver dyad. This is particularly important given that 'family-centred care', which is growing in popularity both in policy and practice in a variety of different settings including home care, particularly emphasises the importance of understanding and incorporating the views of both the patient and care-giver into health decision-making (Institute for Patient- and Family-centered Care 2011).

Furthermore, Epstein and Peters (2009), in their review of patient preference, emphasised the role that physicians play in constructing patient preferences with respect to treatment choices and health decision-making. In fact, shared decision-making between physicians and patients is a core tenet of patient-centred care and is widely supported (Elwyn et al. 2012). Thus, the inclusion of physician perspectives in the current study builds on the established importance of the physician-patient relationship and its implications for treatment preference and adherence as well.

The findings also support previous work on home care which identified the importance of understanding family and client perspectives in order to improve the quality of services provided (Aronson 2004; Geron et al. 2000; Martin-Matthews and Sims-Gould 2008). As well, it builds on work by Alwin, Oberg and Krevers (2010) on the perceptions of informal care-givers supporting patients with dementia and the perceived value of supports related to alleviating care-giver burden.

\section{Limitations}

Study participants were predominantly Caucasian, English-speaking, well-educated and sampled from a single family health team in an affluent urban setting, which may limit the transferability of findings. In addition, this study recruited patients and informal care-givers in dyads, so the experiences of patients without informal care-givers are not captured here. Further, all patients in this study were supported by a multi-disciplinary family health team, which may differ from the experiences of patients who receive care from a single physician practice. Future research in varied primary care settings serving socio-demographically diverse patient populations is needed to 
understand better the salient factors related to the perceived value of informal and formal support for older adults with multi-morbidity for different populations.

\section{Conclusion}

The findings suggest that views of informal and formal support converge on supports that facilitate patient independence and ease care-giver burden. However, important differences emerged regarding how patient independence can be facilitated. As well, a dichotomous perception of informal and formal support was also illuminated, suggesting that patients often overestimate care-giver capacity to provide support and rely too heavily on informal care-givers. This over-reliance may reduce uptake of available formal supports such as a personal support workers and therefore increase the risk of care-giver burnout. Additionally, although a basket of services is offered to patients through home care in Ontario, home-care services were generally assessed as having relatively low importance by all participant groups. The undervaluing of formal supports such as home-care services may be due to perceived necessity and/or the perceived lack of appropriateness of support provided rather than the quality of the available services. As well, the current structuring of support services delivered through home care may also serve as a barrier to uptake. Overall, the findings underscore the importance of understanding the patient context and how this may influence perceived importance of supports.

While the findings emphasise the importance of including the perspectives of patients, informal care-givers and physicians in the process of care delivery, the needs and priorities of these stakeholders may come into conflict. Consideration should be given to areas where stakeholder views converge and diverge in order to strengthen the therapeutic relationship and foster co-operation among stakeholders.

As care is increasingly shifted into the community, with policies emphasising ageing at home, it is important to understand patient context in order to meet effectively the complex health and care needs of older adults with multimorbidity. Many of the participants in this study perceived formal care services as a substitute rather than a support for independence. Given this, policy makers may need to consider how formal home-care services may be organised and provided in a way that does not impinge on patients' autonomy, particularly when care-givers and physicians agree that the patient is at risk for adverse events without such support. Further, given that some care-givers are clearly struggling to keep up with the demands, shifting the perceptions of home-care services from 'care in times of great need' to 'high-value supportive 


\section{Gayathri Naganathan et al.}

services' might improve receptiveness to receiving such services. Additionally, policy makers might consider how better to enable care-giver supports in the context of patients who do not want substitutes for care-givers and do not see the need when care-givers are, at least in some cases, impairing their own health and wellbeing to address the needs of their loved ones. Making services and programmes available in this context needs to be designed in ways that engage patients and care-givers to ensure that the supports are not only available, but are also 'acceptable' to patients and care-givers. Finally, physicians could be made more aware of the importance of social engagement to their patients and to determine if their treatments are aligned with this goal. Although physicians may be at a disadvantage in their influence in this realm of social supports (non-medical issues) for patients and care-givers, but may be able to assist patients and care-givers overcome discrepant views (as trusted advisors). Certainly it is clear that in the group of individuals who participated in this study, moral hazard and excess demand are less a concern than personal desires not to use available services. Clearly, a more nuanced understanding of the perceptions of the unit of care with respect to supports and services offered in the community setting is vital to quality care that allows Canadians to age successfully at home.

\section{Acknowledgements}

The project was funded by the Ontario Ministry of Health and Long-term Care, Health System Performance Research Network Grant. The views expressed in this paper are the views of the authors and do not necessarily reflect those of the funder. The authors gratefully acknowledge the Health System Performance Research Network (\#o6o34) and Project Manager Jessica Goncalves for supporting the study reported in this paper. The researchers extend their gratitude to the physicians, family care-givers, patients and staff at the Sunnybrook Family Health Team (Toronto) for their time and dedication to the project reported in this paper. The project received ethics approval from the Research Ethics Board of Sunnybrook Health Sciences Centre (project number 374-2011). All authors contributed to the design of the study, and review and writing of the manuscript. Authors GN, KK and AG implemented the protocol and completed the analysis of the findings. The authors do not have any conflicts of interest.

\section{References}

Alwin, J., Oberg, B. and Krevers, B. 2010. Support/services among family caregivers of persons with dementia-perceived importance and services received. International Journal of Geriatric Psychiatry, 25, 3, 240-8.

Aronson, J. 2004. 'You need them to know your ways': service users' views about valued dimensions of home care. Home Health Care Services Quarterly, 22 , 4, 85-98. 
Byrne, K., Frazee, K., Sims-Gould, J. and Martin-Matthews, A. 201 2. Valuing the older person in the context of delivery and receipt of home support: client perspectives. Journal of Applied Gerontology, 31, 3, 377-401.

Canadian Institute for Health Information 2011. Health Care in Canada, 20II: A Focus on Seniors and Aging. Canadian Institute for Health Information. Available online at https://secure.cihi.ca/free_products/HCIC_2011_seniors_report_en. pdf [Accessed 17 July 2014].

Canadian Institute for Health Information 2013. Home Care. Canadian Institute for Health Information. Available online at http://www.cihi.ca/CIHI-ext-portal/ internet/EN/TabbedContent/types+of+care/community+care/home+care/ cihio21338 [Accessed 24 July 2014].

Chan, S., Hiebert, D., Addario, S. D. and Sherrell, K. 2005. The Profile of Absolute and Relative Homelessness Among Immigrants, Refugees, and Refugee Claimants in the GVRD. MOSAIC, University of British Columbia. Available online at http://www.urban centre.utoronto.ca/pdfs/elibrary/HLN-among-Immigrants-Vancou.pdf [Accessed 14 May 2014].

Chappell, N.L. and Funk, L. M. 2011. Social support, caregiving, and aging. Canadian Journal on Aging $=L$ a revue canadienne du vieillissement, 3o, 3, 355-70.

Elwyn, G., Frosch, D., Thomson, R., Joseph-Williams, N., Lloyd, A., Kinnersley, P., Cording, E., Tomson, D., Dodd, C., Rollnick, S., Edwards, A. and Barry, M. 2012. Shared decision making: a model for clinical practice. Journal of General Internal Medicine, 27, 10, 1361-7.

Epstein, R. M. and Peters, E. 2009. Beyond information: exploring patients' preferences. JAMA: The Journal of the American Medical Association, 302, 2, $195^{-7}$.

Etters, L., Goodall, D. and Harrison, B. E. 2008. Caregiver burden among dementia patient caregivers: a review of the literature. Journal of the American Academy of Nurse Practitioners, 2o, 8, 423-8.

Fortin, M., Bravo, G., Hudon, C., Vanasse, A. and Lapointe, L. 2005. Prevalence of multimorbidity among adults seen in family practice. Annals of Family Medicine, 3, 3, 223-8.

Geron, S. M., Smith, K., Tennstedt, S., Jette, A., Chassler, D. and Kasten, L. 2ooo. The home care satisfaction measure: a client-centered approach to assessing the satisfaction of frail older adults with home care services. Journals of Gerontology: Psychological Sciences and Social Sciences, 55B, 5 , S259-70.

Glynn, L. G., Valderas, J. M., Healy, P., Burke, E., Newell, J., Gillespie, P. and Murphy, A. W. 2011. The prevalence of multimorbidity in primary care and its effect on health care utilization and cost. Family Practice, 28, 5, 516-23.

Green, J. and Thorogood, N. 2009. Qualitative Methods for Health Research. Second edition, Sage, Thousand Oaks, California.

Haapanen, N., Miilunpalo, S., Pasanen, M., Oja, P. and Vuori, I. 1997. Agreement between questionnaire data and medical records of chronic diseases in middle-aged and elderly Finnish men and women. American Journal of Epidemiology, 145, 8, 762-9.

Iecovich, E. and Biderman, A. 2013. Concordance between self-reported and physician-reported chronic co-morbidity among disabled older adults. Canadian Journal on Aging = La revue canadienne du vieillissement, 32, 3, 287-97.

Institute for Patient- and Family-centered Care 201 1. Advancing the Practice of Patientand Family-Centered Care in Primary Care and Other Ambulatory Settings: How to Get Started. Institute for Patient- and Family-Centered Care. Available online at http://www.ipfcc.org/pdf/GettingStarted-AmbulatoryCare.pdf [Accessed 12 May 2014].

König, H.-H., Leicht, H., Bickel, H., Fuchs, A., Gensichen, J., Maier, W., Mergenthal, K., Riedel-Heller, S., Schäfer, I., Schön, G., Weyerer, S., Wiese, B., 


\section{Gayathri Naganathan et al.}

van den Bussche, H., Scherer, M. and Eckardt, M. 2013. Effects of multiple chronic conditions on health care costs: an analysis based on an advanced treebased regression model. BMC Health Services Research, 13, 219, 1-13.

Kriegsman, D. M.W., Penninx, B.W.J.H., van Eijk, J.T. M., Boeke, A.J.P. and Deeg, D. J. H. 1996. Self-reports and general practitioner information on the presence of chronic diseases in community dwelling elderly: a study on the accuracy of patients' self-reports and on determinants of inaccuracy. Journal of Clinical Epidemiology, 49, 12, 1407-1 7.

Kuluski, K., Bensimon, C., Alvaro, C., Schaink, A., Lyons, R. and Tobias, R. 2014. Life interrupted: a qualitative exploration of the impact of complex chronic disease on the daily lives of patients receiving complex continuing care. Illness, Crisis $\mathcal{E} \mathcal{O}$ Loss, 22, 2, 127-44.

Kuluski, K., Gill, A., Naganathan, G., Upshur, R., Jaakkimainen, R. L. and Wodchis, W. P. 2013a. A qualitative descriptive study on the alignment of care goals between older persons with multi-morbidities, their family physicians and informal caregivers. BMC Family Practice, 14, 133, 1-10.

Kuluski, K., Hoang, S. N., Schaink, A. K., Alvaro, C., Lyons, R. F., Tobias, R. and Bensimon, C. M. 2013 $b$. The care delivery experience of hospitalized patients with complex chronic disease. Health Expectations 16, 4, e1 11 1-23.

Kuluski, K., Williams, A. P., Laporte, A. and Berta, W. 2012. The role of communitybased care capacity in shaping risk of long-term care facility placement. Healthcare Policy, 8, 1, 92-105.

Kwag, K. H., Martin, P., Russell, D., Franke, W. and Kohut, M. 2011 . The impact of perceived stress, social support, and home-based physical activity on mental health among older adults. International Journal of Aging and Human Development, 72, 2, $137-54$.

Kwan, B. M., Dimidjian, S. and Rizvi, S. L. 2010. Treatment preference, engagement, and clinical improvement in pharmacotherapy versus psychotherapy for depression. Behaviour Research and Therapy, 48, 8, 799-804.

Lehnert, T., Heider, D., Leicht, H., Heinrich, S., Corrieri, S., Luppa, M., RiedelHeller, S. and König, H.-H. 2011 . Review: health care utilization and costs of elderly persons with multiple chronic conditions. Medical Care Research and Review, 68, 4, 387-420.

Lilly, M. B., Robinson, C., Holtzman, S. and Bottorff, J. L. 201 2. Can we move beyond burden and burnout to support the health and wellness of family caregivers to persons with dementia? Evidence from British Columbia, Canada. Health $\mathcal{E}^{\circ}$ Social Care in the Community, 2o, 1, 103-12.

Lopez, R. P., Mazor, K. M., Mitchell, S. L. and Givens, J. L. 2013. What is family-centered care for nursing home residents with advanced dementia? American Journal of Alzheimer's Disease and Other Dementias, 28, 8, 763-68.

Maier, H. and Klumb, P. L. 2005. Social participation and survival at older ages: is the effect driven by activity content or context? European Journal of Ageing, 2, 1, $3^{1-9}$.

Martin-Matthews, A. and Sims-Gould, J. 2008. Employers, home support workers and elderly clients: identifying key issues in delivery and receipt of home support. Healthcare Quarterly, 11, 4, 69-75.

Martin-Matthews, A., Sims-Gould, J. and Tong, C. E. 2013. Canada's complex and fractionalized home care context: perspectives of workers, elderly clients, family carers, and home care managers. Canadian Review of Social Policy, $\mathbf{2 0 1 3}, 68 / 69,55^{-74}$.

Maslow, A. H. 1943. A theory of human motivation. Psychological Review, 5o, 4, 370-96. 
Mercer, K. 2008. Facilitating organizational mergers: amalgamation of community care access centres. Journal of Health Services Research $\mathcal{E}$ Policy, 13, supplement 1, $4^{6-} 5^{1 .}$

Ministry of Health and Long-term Care 2006. CCAC Home Care Services. In CCAC Client Services Policy Manual. Ministry of Health and Long-term Care, Toronto, $1-21$.

Ministry of Health and Long-term Care 2010. Aging at Home Strategy. Ministry of Health and Long-term Care. Available online at http://news.ontario.ca/ mohltc/en/2010/o8/aging-at-home-strategy.html [Accessed 20 August 2014].

Money, A. G., Barnett, J., Kuljis, J. and Lucas, J. 2013. Patient perceptions of epinephrine auto-injectors: exploring barriers to use. Scandinavian Journal of Caring Sciences, 27, 2, 335-44.

Okura, Y., Urban, L. H., Mahoney, D. W., Jacobsen, S. J. and Rodeheffer, R. J. 2004. Agreement between self-report questionnaires and medical record data was substantial for diabetes, hypertension, myocardial infarction and stroke but not for heart failure. Journal of Clinical Epidemiology, 57, 10, 1096-103.

Ontario Medical Association 2010. Patient-Centred Care. Ontario Medical Review, June, 34-49.

Qian, H., Li, G.-b., Chen, H.-x. and Zhang, D.-1. 2011. An exploratory research of patient perceived value in China. Journal of Medical Marketing: Device, Diagnostic and Pharmaceutical Marketing, 1 1, 4, 277-83.

Rizza, A., Kaplan, V., Senn, O., Rosemann, T., Bhend, H. and Tandjung, R. 2012. Age- and gender-related prevalence of multimorbidity in primary care: the Swiss FIRE project. BMC Family Practice, 13, $113,1-9$.

Schultz, H., Westberg, S. M., de Oliveira, D. R. and Brummel, A. 201 2. Patient-perceived value of Medication Therapy Management (MTM) services: a series of focus groups. Innovations in Pharmacy, 3, 4, 1-8.

Shier, G., Ginsburg, M., Howell, J., Volland, P. and Golden, R. 2013. Strong social support services, such as transportation and help for caregivers, can lead to lower health care use and costs. Health Affairs (Project Hope), 32, 3, 544-51.

Sims-Gould, J. and Martin-Matthews, A. 2010. We share the care: family caregivers' experiences of their older relative receiving home support services. Health $\mathcal{E}^{2}$ Social Care in the Community, 18, 4, 41 $5^{-23}$.

Sinha, S. K. 2013. Living Longer, Living Well: Highlights and Key Recommendations from the Report Submitted to the Minister of Health and Long-term Care and the Minister Responsible for Seniors on Recommendations to Inform a Seniors Strategy for Ontario. Ontario Ministry of Health and Long-term Care. Available online at http://www. health.gov.on.ca/en/common/ministry/publications/reports/seniors_strategy/docs/ seniors_strategy.pdf [Accessed 5 July 2014 ].

Surbone, A., Baider, L. and Kagawa-Singer, M. 2010. Cultural competence in the practice of patient-family-centered geriatric oncology. Journal of Geriatric Oncology, 1, 2, $45^{-7}$.

Thomas, D. R. 20o6. A general inductive approach for analyzing qualitative evaluation data. American Journal of Evaluation, 27, 2, 237-46.

Tomaka, J., Thompson, S. and Palacios, R. 2006. The relation of social isolation, loneliness, and social support to disease outcomes among the elderly. Journal of Aging and Health, 18, 3, 359-84.

Toronto Transit Commission 2015. Wheel-Trans. Toronto Transit Commission. Available online at https://ttc.ca/WheelTrans/index.jsp [Accessed 23 February 2015 ].

United Nations Department of Economic and Social Affairs, Population Division 2013. World Population Ageing 2OI3. United Nations. Available online at http:// 


\section{Gayathri Naganathan et al.}

www.un.org/en/development/desa/population/publications/pdf/ageing/

WorldPopulationAgeing2013.pdf [Accessed 28 April 2014].

Ward, B. W. and Schiller, J.S. 2013. Prevalence of multiple chronic conditions among US adults: estimates from the National Health Interview Survey, 2010. Preventing Chronic Disease, 10, E65.

Warner, L. M., Ziegelmann, J.P., Schüz, B., Wurm, S., Tesch-Römer, C. and Schwarzer, R. 2011. Maintaining autonomy despite multimorbidity: self-efficacy and the two faces of social support. European Journal of Ageing, 8, 1, 3-1 2.

Watsford, C. and Rickwood, D. 2014. Young people's expectations, preferences, and experiences of therapy: effects on clinical outcome, service use, and help-seeking intentions. Clinical Psychologist, 18, 1, 43-51.

Williams, A. P., Challis, D., Deber, R., Watkins, J., Kuluski, K., Lum, J. M. and Daub, S. 2009a. Balancing institutional and community-based care: why some older persons can age successfully at home while others require residential long-term care. Longwoods Review, 7, 1, 95-105.

Williams, A. P., Lum, J. M., Deber, R., Montgomery, R., Kuluski, K., Peckham, A., Watkins, J., Williams, A., Ying, A. and Zhu, L. 20ogb. Aging at home: integrating community-based care for older persons. Healthcare Papers, 10, 1, 8-21.

World Health Organization 2011. Global Status Report on Noncommunicable Diseases 2ого. World Health Organization. Available online at http://www.who.int/ $\mathrm{nmh} /$ publications/ncd_report_full_en.pdf [Accessed 18 August 2014].

Yach, D., Hawkes, C., Gould, C. L. and Hofman, K. J. 2004. The global burden of chronic diseases: overcoming impediments to prevention and control. JAMA: The Journal of the American Medical Association, 291, 21, 2616-22.

$\mathrm{Yu}, \mathrm{J} .2011$. Home care utilization patterns among the elderly population: a case study of Ontario, Canada. Queen's University. Available online at http://hdl. handle.net/1974/6523 [Accessed 18 August 2014].

Zhu, S., Hu, J. and Efird, J. T. 2012. Role of social support in cognitive function among elders. Journal of Clinical Nursing, 21, 15/16, 2118-25.

Accepted I 8 June 20I5; first published online 3 August 2015

Address for correspondence:

Gayathri Naganathan, Institute of Health Policy,

Management \& Evaluation,

University of Toronto, 155 College Street, Suite 425 ,

Toronto, ON, Canada, $\mathrm{M}_{5} \mathrm{~T}{ }_{3} \mathrm{M} 6$

E-mail: gayathri.naganathan@mail.utoronto.ca 